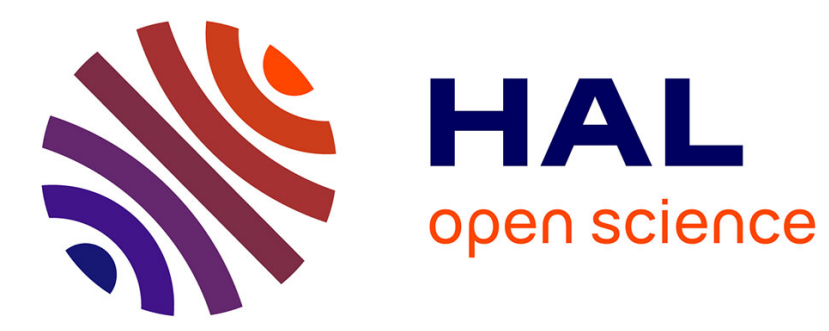

\title{
Thrust wedges and fluid overpressures: Sandbox models involving pore fluids
}

Régis Mourgues, P.R. Cobbold

\section{To cite this version:}

Régis Mourgues, P.R. Cobbold. Thrust wedges and fluid overpressures: Sandbox models involving pore fluids. Journal of Geophysical Research: Solid Earth, 2006, 111 (B5), pp.B05404. 10.1029/2004JB003441 . hal-00115950

\section{HAL Id: hal-00115950 \\ https://hal.science/hal-00115950}

Submitted on 29 Mar 2016

HAL is a multi-disciplinary open access archive for the deposit and dissemination of scientific research documents, whether they are published or not. The documents may come from teaching and research institutions in France or abroad, or from public or private research centers.
L'archive ouverte pluridisciplinaire $\mathbf{H A L}$, est destinée au dépôt et à la diffusion de documents scientifiques de niveau recherche, publiés ou non, émanant des établissements d'enseignement et de recherche français ou étrangers, des laboratoires publics ou privés. 


\title{
Thrust wedges and fluid overpressures: Sandbox models involving pore fluids
}

\author{
R. Mourgues ${ }^{1,2}$ and P. R. Cobbold ${ }^{1}$ \\ Received 20 September 2004; revised 11 August 2005; accepted 9 December 2005; published 6 May 2006.
}

[1] The well-known model for the critical taper of an accretionary wedge includes overpressure as a first-order parameter. Fluid overpressures reduce frictional resistance at the base of a wedge but they also act as body forces on all material particles of the wedge, in addition to that of gravity. By means of sandbox modeling, many workers have tried to verify the predictions of the critical taper model, but few of them have so far incorporated true fluid pressures. We have used scaled experiments, in which compressed air flows through sand packs, so as to model the deformation of overpressured wedges. A new apparatus provides for a horizontally varying fluid pressure, for example, a linear variation, as in the critical taper model. We have done three series of experiments, involving horizontal shortening of homogeneous or multilayered sand models for various gradients of fluid pressure. As predicted by the critical taper model, the apical angle of the resulting wedge depends on the overpressure gradient. In homogeneous sand at a high overpressure gradient, deformation becomes diffuse and looks ductile. In multilayered models, detachments form beneath layers of low permeability, so that thrusts propagate rapidly toward the undeformed foreland. The efficiency of a detachment and its ability to propagate depend not only on the fluid pressure but also on the permeability ratios between the various layers.

Citation: Mourgues, R., and P. R. Cobbold (2006), Thrust wedges and fluid overpressures: Sandbox models involving pore fluids, J. Geophys. Res., 111, B05404, doi:10.1029/2004JB003441.

\section{Introduction}

[2] Thin-skinned thrust belts and accretionary wedges form by horizontal shortening and vertical thickening of sedimentary strata, in response to horizontal compression, for example at convergent plate margins (Figure 1). Thrust faulting is the main mechanism of deformation. If the rock fails according to a Coulomb frictional criterion and its cohesion is small, it can be shown theoretically that the wedge will adopt a triangular shape [Davis et al., 1983; Dahlen, 1990]. The apical angle of the wedge depends on both the internal and basal resistances to frictional sliding. In many natural examples, a small apical angle and a wide spacing of internal thrusts suggest a small resistance to sliding at the base. This may due to (1) an unusually low coefficient of friction, (2) a ductile layer (e.g., salt), which deforms slowly [Davis and Engelder, 1985], or (3) fluid overpressure, which carries part of the vertical load, so reducing the frictional resistance [Hubbert and Rubey, 1959].

[3] Accretionary wedges and thrust belts are mechanically similar, but they differ according to the age and history of

\footnotetext{
${ }^{1}$ Géosciences-Rennes, UMR 6118, Université de Rennes 1, Rennes, France.

${ }^{2}$ Now at Laboratoire de Géodynamique des Rifts et des Marges Passives, University of Le Mans, Le Mans, France.

Copyright 2006 by the American Geophysical Union. 0148-0227/06/2004JB003441\$09.00
}

accreted sediment [J. C. Moore et al., 1990]. True accretionary wedges form in submarine settings, next to subduction zones. Good active examples are the Barbados wedge [Moore et al., 1988, 1995; Brown and Westbrook, 1988; Shi and Wang, 1988; Bekins et al., 1994; Moore and Tobin, 1997; Maltman et al., 1997; Bangs et al., 1999; Henry, 2000], the Nankai wedge [G. F. Moore et al., 1990; Taira et al., 1992; Saffer and Bekins, 1988; Bangs et al., 2004], the Makran [Minshull et al., 1992; Kopp et al., 2000; Schlüter et al., 2002] and the Cascadia wedge [J. C. Moore et al., 1990]. Over the last few decades, the Ocean Drilling Program (ODP) and others of a kind have investigated accretionary wedges, so as better to understand fluid circulation and its interaction with detachment zones. In the Nankai wedge, drilling succeeded in penetrating the main detachment, revealing a high porosity in the underthrust sediment [Taira et al., 1992]. In the Barbados wedge, high pore fluid pressures were estimated from both consolidation tests and logging data [Moore et al., 1995]. Moore and Tobin [1997] have estimated that fluid pressures are close to the lithostatic stress, from a depth of $200 \mathrm{~m}$ below sea level, down to the main detachment at $300 \mathrm{~m}$ (Figure 2). Bangs et al. [1999] have shown that the detachment propagates along a layer of radiolarian-rich Miocene mudstone, 30-40 m thick, which has anomalously high values of porosity (up to $70 \%$ ) and fluid content, probably as a result of overpressures. Independent evidence for overpressure is provided by the widespread occurrence of mud volcanoes [Brown and Westbrook, 1988]. 


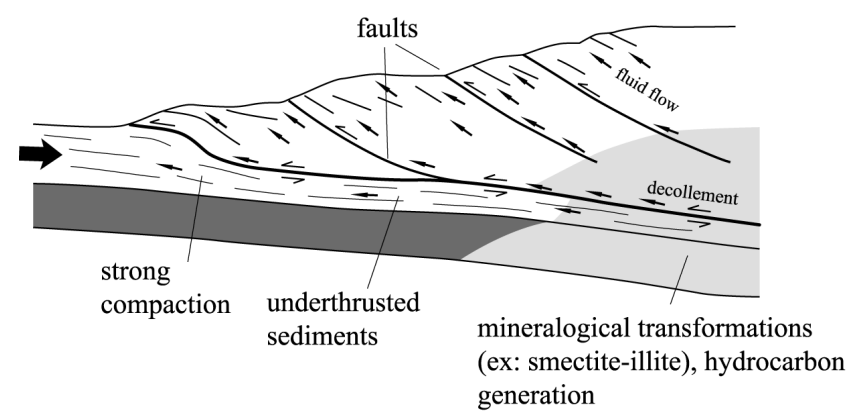

Figure 1. Idealized section of an accretionary wedge, showing mechanisms involved in generation of fluid overpressures (modified after Moore and Vrolijk [1992]).

[4] In accretionary wedges, overpressures arise through various mechanisms. At the front of a wedge, young sediment is saturated with water [Maltman et al., 1997]. It may be subject to strong compaction (Figure 1). As the solid framework collapses, pore water is expelled. In mudstone, which has low permeability, the expulsion is slow, so that fluid pressures build up to high values, close to the lithostatic pressure [Moore et al., 1995; Moore and Tobin, 1997]. This process is known as disequilibrium compaction. In contrast, highly permeable layers (such as sand) act as drains, so that fluid pressures remain closer to hydrostatic.

[5] Disequilibrium compaction is less important at the back of an accretionary wedge, and in onland thrust belts, where sediments are older and, for the most part, already lithified. However, overpressures may also arise through chemical transformations. One such transformation is smectite to illite [Moore et al., 1988; Moore and Vrolijk, 1992; Bekins et al., 1994, 1995; Osborne and Swarbrick, 1997; Swarbrick et al., 2002]. This is thought to be efficient when temperatures reach $70-150^{\circ} \mathrm{C}$ [Swarbrick et al., 2002]. It releases not only free water, but also solutes, some of which may precipitate within pore spaces, decreasing the permeability. Another important transformation is of organic material to methane or other hydrocarbons [Brown and Westbrook, 1988; Moore et al., 1988; Cobbold, 1999; Henry, 2000; Swarbrick et al., 2002; Echevarria et al., 2003]. Many workers have found traces of thermogenic methane in the frontal detachments of accretionary wedges [Moore and Vrolijk, 1992]. The inference is that hydrocarbons generate at the back of the wedge and that fluids flow rapidly along the detachment [Henry, 2000]. The high thermal flux measured in the Barbados and Nankai accretionary wedges is suspected to cause hydrocarbon generation and even cracking of oil to gas [Taira et al., 1992; Henry, 2000].

[6] As a result of all these mechanisms, the pore fluid pressure is expected to increase with depth and therefore with distance along the base of a wedge. Many numerical models have predicted such an increase, for a thickening wedge [Shi and Wang, 1988; Bekins et al., 1995; Saffer and Bekins, 1988]. As a first approximation, it is reasonable to assume that the increase is linear, although in reality it may be more complex.

[7] In the well-known theory of critical taper, overpressure is a first-order parameter, and it is assumed to vary linearly with depth [Davis et al., 1983; Dahlen, 1984; Dahlen et al., 1984; Dahlen and Barr, 1989; Dahlen, 1990]. One way to verify the general predictions of the theory is by sandbox modeling [Davis et al., 1983; Malavieille, 1984; Mulugeta, 1988; Colletta et al., 1991; Liu et al., 1992; Mulugeta and Koyi, 1992; Lallemand et al., 1994; Gutscher et al., 1996, 1998a, 1998b; Storti et al., 1997; Couzens-Schultz et al., 2003; Lohrmann et al., 2003; Ellis et al., 2004; Adam et al., 2005]. The results have borne out one important theoretical prediction that small shear stresses at the base of the wedge result in a small apical angle. To obtain sufficiently small shear stresses, some experimenters have resorted to a thin layer of silicone putty, a low-friction granular material, or even a smooth plate at the base of the model.

[8] The use of true pore fluids in quantitative sandbox modeling is a more recent development. Cobbold and Castro [1999] showed that it was feasible to use compressed air for this purpose and Cobbold et al. [2001] applied the new technique to the formation of thrust wedges. Mourgues and Cobbold [2003] showed how seepage forces, due to fluid overpressures, modify stress orientations and the dips of normal faults. Cobbold et al. [2001] verified that fluid overpressure modifies the apical angle of a thrust wedge and they also showed that layers of small permeability (fine sand or loess) promote detachments. However, for practical reasons, they sectioned their models horizontally, not vertically, and this led to a significant lack of resolution in the description of internal structures. Moreover, in their apparatus, fluid pressure was uniform at the base of the model. Such a simple boundary condition would appear to be unrealistic for wedges in nature.

[9] We have therefore modified the experimental apparatus. The new configuration provides for vertical sectioning and for a horizontally variable fluid pressure at the base of the model. After a preliminary discussion of the effect of fluid pressure in the critical taper model, we introduce the new apparatus. Then we describe three series of experiments, which involved horizontal shortening of homoge-

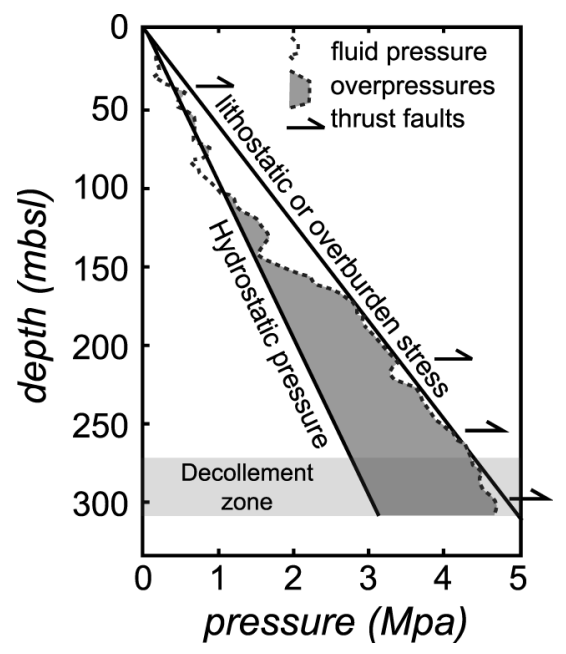

Figure 2. Pressure profile for pore fluid at the toe of the Barbados wedge (modified after Moore and Tobin [1997]). 


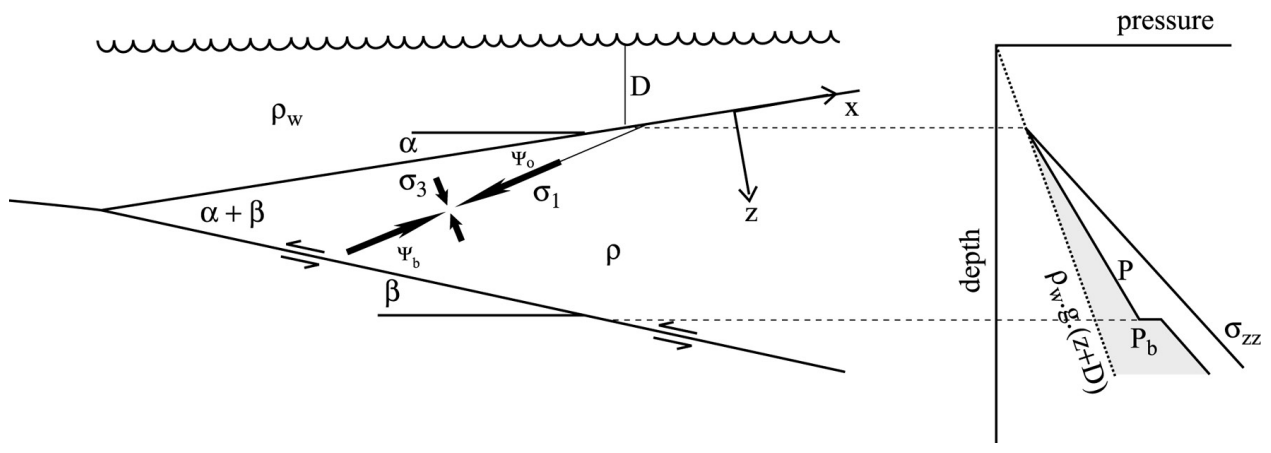

Figure 3. Main elements of the critical taper model for a submerged wedge (modified after Dahlen [1990] with permission from the Annual Review of Earth and Planetary Sciences, volume 18 (C) 1990 by Annual Reviews, www.annualreviews.org).

neous or multilayered sand, for various vertical gradients of basal fluid pressure.

\section{Effects of Fluid Pressure in the Critical Taper Model}

[10] In the critical taper model [Davis et al., 1983; Dahlen, 1990], the parameter $\lambda$ provides a dimensionless measure of fluid pressure:

$$
\lambda=\frac{P-\rho_{w} g D}{\sigma_{z z}-\rho_{w} g D}
$$

Here $P$ is the fluid pressure, $\rho_{w}$ is the density of water, and $D$ is the depth of the submerged wedge (Figure 3 ). If the fluid is in a hydrostatic state and has a density of $1000 \mathrm{~kg} \mathrm{~m}^{-3}$, whereas the saturated rock has an average density of $2500 \mathrm{~kg} \mathrm{~m}^{-3}$, then $\lambda=0.4$. Some authors [e.g., Shi and Wang, 1988; Saffer and Bekins, 1988] prefer to use the parameter $\lambda^{*}$, which more directly reveals an abnormal pressure:

$$
\lambda^{*}=\frac{P-\left.P\right|_{h}}{\sigma_{z z}-\left.P\right|_{h}}
$$

Here $\left.P\right|_{h}$ is the hydrostatic part of the total fluid pressure, so that $\lambda^{*}>0$ expresses an overpressure. In the critical taper model, it is convenient to distinguish $\lambda$, the fluid pressure in the body of the wedge, from $\lambda_{b}$, the fluid pressure on the basal detachment. For a noncohesive wedge, there is an exact solution, which relates the angle of taper to the orientation of the internal stress [Dahlen, 1990, equation 74]:

$$
\alpha+\beta=\Psi_{o}+\Psi_{b}
$$

Here, $\alpha$ is the dip of the upper surface of the wedge; $\beta$ is the dip of the basal detachment; and $\psi_{\mathrm{o}}$ and $\psi_{\mathrm{b}}$ are the angles between these two surfaces and the greatest principal stress (Figure 3). Equation (3) represents a self-similar solution, in which the angles above are constant throughout the wedge, as are the values of $\lambda$ and $\lambda_{b}$. Equation (3) may be written more explicitly, in terms of fluid overpressures and material properties, both within the wedge and at its base, but the form is complex.
[11] Dahlen [1990, equation 86] has also derived an approximate and more explicit expression for a noncohesive submerged wedge, which has a narrow taper and an efficient detachment at its base, so that $\mu_{b}\left(1-\lambda_{b}\right)<\mu(1-\lambda)$, where $\mu$ and $\mu_{b}$ are the coefficients of internal friction in the wedge and on the detachment:

$$
\alpha+\beta=\frac{\left(1-\rho_{w} / \rho\right) \beta+\mu_{b}\left(1-\lambda_{b}\right)}{(1-\rho w / \rho)+2(1-\lambda)[\sin \phi /(1-\sin \phi)]}
$$

Here $\rho$ is the bulk density and $\phi$ is the angle of internal friction of the material, so that $\mu=\tan \phi$.

[12] In the exact solution (3), the angle of taper decreases, as the internal and basal overpressures increase together (Figure 4a), or as the basal overpressure alone increases (Figure $4 \mathrm{~b}$ ). In contrast, the angle of taper increases, as the internal overpressure alone increases (Figure 4c). On comparing the approximate solution (4) to the exact solution (3), we see that they are almost identical, for moderate overpressures and for angles of taper smaller than $4^{\circ}$ (Figure $4 \mathrm{c}$ ). The results show that the overpressure on the detachment and the overpressure within the wedge have somewhat different mechanical effects. In equation (4), an increase in $\lambda_{b}$ reduces the numerator, by reducing the effective coefficient of friction on the detachment to a value of $\mu_{b}^{\prime}=\mu_{b}\left(1-\lambda_{b}\right)$, whereas an increase in $\lambda$ reduces the denominator, but in a different way and to a significantly greater extent. To illustrate the difference, we have again plotted the angle of taper as a function of fluid pressure (Figure $4 \mathrm{c}$, gray curves), but this time we have taken $\mu^{\prime}=$ $\mu(1-\lambda)$ as a measure of internal friction for the material in the wedge. The resulting curves are noticeably higher than the true ones, showing that the measure is inadequate.

[13] The effect of $\lambda$ on the stability of a wedge is due to seepage forces, in other words, gradients of fluid overpressure [Dahlen, 1990; Mourgues and Cobbold, 2003]. The fluid pressure at a point $\mathrm{M}(\mathrm{x}, \mathrm{z})$ in the wedge is the sum of a hydrostatic pressure $\left.P\right|_{h}$ and a nonhydrostatic part $\left.P\right|_{n h}$ :

$$
P(M)=\left.P(M)\right|_{h}+\left.P(M)\right|_{n h}=\rho_{w} g z \cos \alpha+\rho_{w} g D+\left.P(M)\right|_{n h}
$$




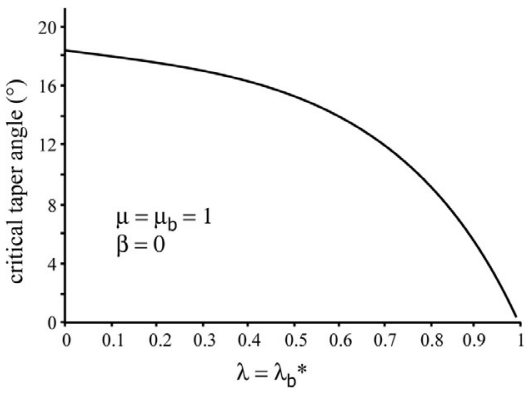

a- Combined effect of fluid overpressures distributed within the wedge and on the basal detachment

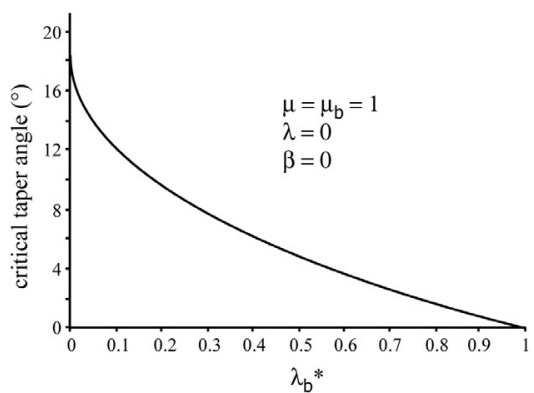

b- Effect of fluid overpressures on the basal detachment

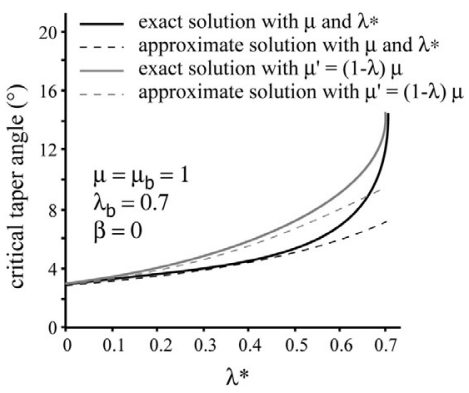

c- Effect of fluid overpressures distributed within the wedge

Figure 4. Critical angle of taper, as a function of fluid overpressure within the wedge $\left(\lambda^{*}\right)$, or at its base $\left(\lambda_{b}^{*}\right)$. Curves represent exact solutions (solid lines) or approximate solutions (dashed lines) of equation (4) in text. They are for a flat base $(\beta=0)$ and fixed material properties $\left(\mu=\mu_{b}=1\right)$. Separate plots are for equal values of (a) internal and basal overpressure, (b) various basal overpressures or (c) various internal overpressures. Dark curves are for true expression (in terms of $\lambda$ and $\mu$ ), whereas light curves are for false expression, assuming $\mu^{\prime}=(1-\lambda) \mu$. For further discussion, see text.

In terms of effective stresses, the equations of equilibrium are

$$
\frac{\partial \sigma_{i j}^{\prime}}{\partial x_{j}}=\rho g_{i}-\frac{\partial P}{\partial x_{i}}
$$

Here $\sigma^{\prime}$ is the effective stress tensor, the subscripts denote Cartesian tensor components, and $\rho=\left(1-\phi_{p}\right) \rho_{s}+\phi \rho_{w}$ is the bulk density, where $\phi_{p}$ is the porosity and $\rho_{s}$ is the solid density. Using equation (5), taking references axes that are parallel and perpendicular to the upper surface of the wedge, and neglecting the third dimension (Figure 3), equations (6) become

$$
\frac{\partial \sigma_{i j}^{\prime}}{\partial x_{j}}=\left(1-\phi_{p}\right)\left(\rho_{s}-\rho_{w}\right) g_{i}-\left.\frac{\partial P}{\partial x_{i}}\right|_{n h}=\rho^{\prime} g_{i}-\left.\frac{\partial P}{\partial x_{i}}\right|_{n h}
$$

Here $\rho^{\prime}=\left(1-\phi_{p}\right)\left(\rho_{s}-\rho_{w}\right)$ is an effective density, which takes into account the buoyancy. The three forces acting on each element of the solid matrix are (1) weight, $\mathbf{F}_{w}=(1-$ $\left.\phi_{p}\right) \rho_{s} \mathbf{g}$, (2) buoyancy force, $\mathbf{F}_{a}=-\left(1-\phi_{p}\right) \rho_{w} \mathbf{g}$, and (3) seepage force, $\mathbf{F}_{s}=-\left.\nabla \mathbf{P}\right|_{\mathbf{n h}}$.

[14] In the critical taper model, $\lambda$ (or $\lambda^{*}$ ) is assumed to be constant in the wedge. This assumption means that $\partial \mathrm{P} /$ $\left.\partial \mathrm{x}\right|_{\mathrm{nh}}=0$. In other words, the isobars for the nonhydrostatic part of the fluid pressure gradient are parallel to the surface (Figure 5). If the fluid is in a hydrostatic state, $\lambda=0.4$ $\left(\lambda^{*}=0\right)$, seepage forces vanish, and the equations of equilibrium (7) are the same as those for a dry wedge of density $\rho$. Immersion of the wedge will not change its stability. In contrast, if $\lambda \neq 0.4\left(\lambda^{*} \neq 0\right)$, seepage forces act in a direction perpendicular to the surface slope. They change the stability of the wedge, by modifying the value and orientation of the resultant body force (Figure 5).

[15] Overpressures on the basal detachment and overpressures distributed within the wedge have different mechanical effects. In analogue models, a small basal friction can be obtained by using silicone putty, slippery granular media, or smooth basal plates. However, in order to
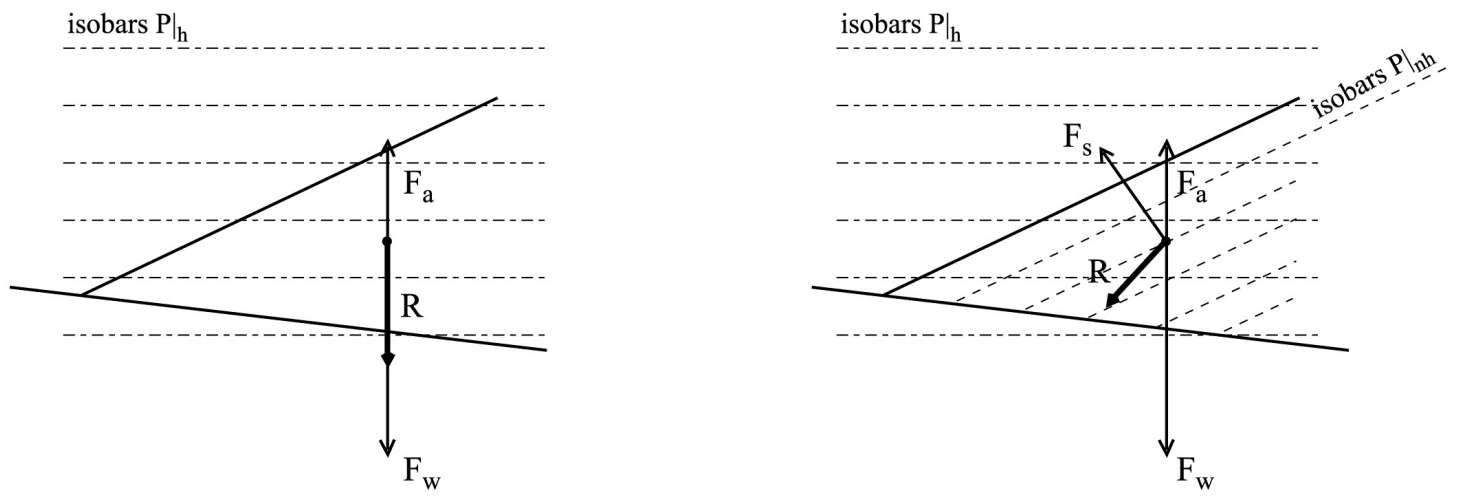

Figure 5. Body forces acting on a submerged wedge, according to whether pore fluid is (left) hydrostatic or (right) overpressured. If fluid is hydrostatic, the relevant body forces are weight $\left(\mathbf{F}_{\mathrm{w}}\right)$ and buoyancy $\left(\mathbf{F}_{\mathrm{a}}\right)$. If there is a gradient of overpressure, an additional seepage force $\left(\mathbf{F}_{\mathbf{s}}\right)$ modifies the resultant body force $(\mathbf{R})$. 
reproduce the body forces due to overpressures in the wedge, it is necessary to use a pore fluid.

\section{Analogue Modeling Involving Pore Fluid}

\subsection{Scaling}

[16] Cobbold and Castro [1999] and Cobbold et al. [2001] injected compressed air into sandbox models from below, generating vertically uniform gradients of overpressure. The scaling of such experiments is based on the equations of equilibrium in term of effective stresses (equations (6)). Each parameter of these equations can be written as a product of a dimensionless quantity (denoted by asterisk) and its reference value (denoted by subscript zero):

$$
\frac{\sigma_{0}}{L_{0} \rho_{b 0} g_{0}} \frac{\partial \sigma_{i j}^{* \prime}}{\partial x_{j}^{*}}=\rho^{*} g^{*}-\frac{P_{0}}{L_{0} \rho_{b 0} g_{0}} \frac{\partial P^{*}}{\partial x_{i}^{*}}
$$

The dimensionless numbers $\sigma_{0} / L_{0} \rho_{0} g_{0}$ and $P_{0} / L_{0} \rho_{0} g_{0}$ must be the same in the model and in the natural prototype. Thus the scaling ratios are

$$
\gamma_{P}=\frac{P_{m}}{P_{r}}=\frac{\sigma_{m}}{\sigma_{r}}=\gamma_{\sigma}=\gamma_{L} \gamma_{\rho} \gamma_{g}
$$

Here

$$
\gamma_{L}=\frac{L_{m}}{L_{r}}, \quad \gamma_{\rho}=\frac{\rho_{m}}{\rho_{r}}, \quad \gamma_{g}=\frac{g_{m}}{g_{r}}=1
$$

In conclusion, fluid pressure and effective stress scale in the same way. So do seepage forces $\left(F_{s}=\left.\nabla P\right|_{n h}\right)$ and gravitational forces $\left(F_{w}=\left(1-\phi_{p}\right) \rho_{s} g\right.$ and $F_{a}=-(1-$ $\left.\left.\phi_{p}\right) \rho_{w} g\right)$. This lays the foundation of scale modeling involving pore fluid [Cobbold et al., 2001].

[17] To obtain a time ratio for their experiments, Cobbold et al. [2001] referred to Darcy's law, which expresses steady fluid flow in a porous medium in response to an overpressure gradient (equation (A9), Appendix A). However, the deformational properties of sand are independent on time. Also, seepage forces do not depend on the rate of fluid flow. They reflect only on the abnormal pressure gradient $\left(\mathbf{F}_{\mathrm{s}}=\left.\nabla \mathbf{P}\right|_{\text {nh }}\right)$. Under these conditions, a suitable choice of permeability sets the time ratio. On the other hand, if we want to model transitory phenomena, such as the production or dissipation of overpressure, the problem becomes more complex. In fact, it is not practical to model these phenomena by using water or air as a pore fluid in sand (Appendix A). The reference time for diffusion of pressure in a model a few centimeters thick is around $10^{-3} \mathrm{~s}$. So, if the rate of deformation of a model is a few centimeters per hour, no overpressure will develop. In other words, the fluid will flow as if in a steady state. The distribution of overpressure in the model will depend only on the boundary conditions. Under these conditions, there is no difference between using water as a pore fluid or using air. Nevertheless, for practical reasons, it is easier to use air.

[18] We assume that the wedge deforms in a purely brittle way, according to the Coulomb yield criterion:

$$
\tau_{f}=c+\mu \cdot \sigma_{n}^{\prime}
$$

Here $\tau_{f}$ and $\sigma_{n}{ }^{\prime}$ are the shear stress and the effective normal stress acting on a fault. The coefficient of internal friction $\mu$ is dimensionless. In contrast, the cohesion $c$ has the dimensions of stress and scales accordingly. If we wish to study a natural system, which is $3 \mathrm{~km}$ thick and has a bulk density of $\rho=2500 \mathrm{~kg} \mathrm{~m}^{-3}$ and a cohesion of about $10 \mathrm{MPa}$ [Cobbold et al., 2001], by means of a model, which is $3 \mathrm{~cm}$ thick and has a density of $\rho=1500 \mathrm{~kg} \mathrm{~m}^{-3}$, our model material must also have a cohesion of around $60 \mathrm{~Pa}$. Dry sand, which indeed has a small cohesion, is a good analogue material for this purpose [Cobbold and Castro, 1999].

\subsection{Experimental Apparatus and Boundary Conditions}

[19] In the critical taper model, $\lambda^{*}$ is assumed to be constant in the wedge. This means that the overpressure increases linearly, both with depth and along the base of the wedge, so that the isobars for overpressure are parallel to its upper surface (Figure 5). This is also a good first approximation to what happens in nature. We have therefore devised a simple apparatus for reproducing it. In this apparatus, there is a steady source of overpressured fluid beneath the model, but not within it. As a result, the overpressure increases linearly with depth and Darcy flow occurs within the model.

[20] Cobbold et al. [2001] built their models in a rectangular box. The sides were of transparent plastic material and the bottom was a sieve. The latter rested on a pressure chamber, which provided a uniform fluid pressure at the base of the model (Figure 6a). This uniformity was probably unrealistic.

[21] In a homogeneous sand model, if the basal fluid pressure is constant, the isobars should form a characteristic fan (Figure 6b), so that $\lambda^{*}$ decreases by $50 \%$ toward the back of the wedge (Figure 6c). To avoid such a decrease, we modified the apparatus. As before, the models lie in a rectangular box $(20 \mathrm{~cm}$ by $30 \mathrm{~cm})$. However, to reduce lateral friction, the sides are of glass. The box rests on an array of tubes, $20 \mathrm{~cm}$ wide, $1.7 \mathrm{~cm}$ thick and $30 \mathrm{~cm}$ high (Figure 6d). The array lies on a pressure chamber, which provides a uniform pressure at the base of the tubes. The tubes are full of sand and they serve as buffers, which regulate fluid flow between pressure chamber and model. Where the model is thicker, the fluid pressure at its base is higher (Figure 6e). In other words, the fluid pressure varies laterally, according to the total thickness of the model. The ratio $\lambda^{*}$ is nearly constant throughout the wedge (Figure 6f), as assumed by Dahlen [1990] for his critical taper model.

\subsection{Materials}

[22] Following Cobbold et al [2001], we used sieved fractions of Fontainebleau sand, of various grain sizes (labeled sands 1,2, and 3). They had different values of permeability (Table 1). Between coarse and fine sand, the permeability ratio was about $4: 1$. In natural environments, the permeability may vary by several orders of magnitude, from $10^{2}$ darcy, for sandy sediment, to $10^{-6}$ darcy or less, for shale. In analogue experiments, it may not be possible to reproduce such a variation in permeability, while respecting the conditions for proper dynamic scaling. The problem is that as the grain size of sand decreases below $50 \mu \mathrm{m}$, the cohesion increases, because of humidity and 


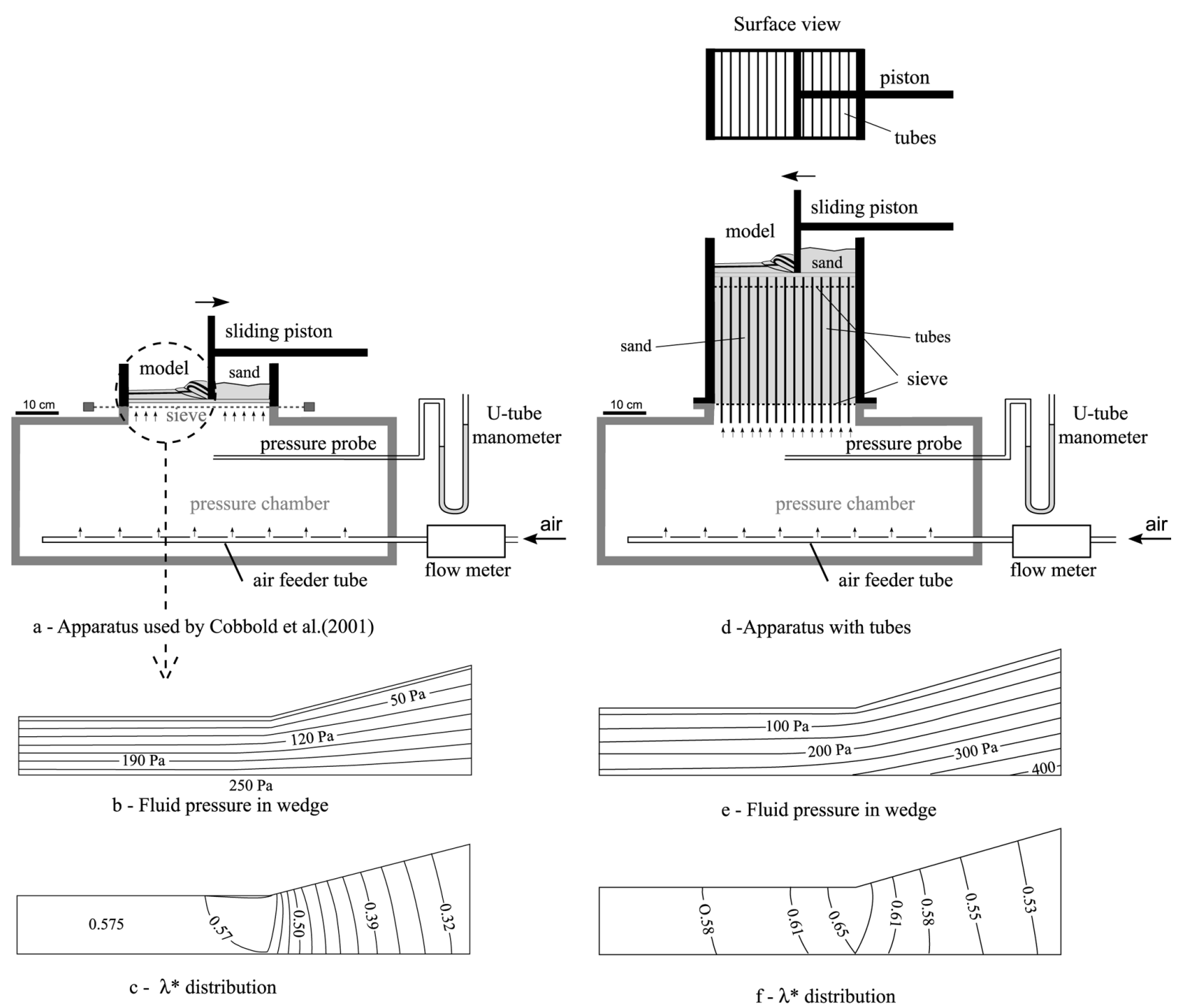

Figure 6. Apparatus and associated fluid pressure distributions in sand models. (a) Simple apparatus of Cobbold et al. [2001], (b) constant fluid pressure over base of model, and (c) decrease of ratio $\lambda^{*}$ as wedge thickens. (d) New apparatus, (e) sand-filled tubes allowing for inhomogeneous fluid pressure at base of model, and (f) quasi-constant value of $\lambda^{*}$ within wedge.

electrostatic attraction. We discuss the effects of such a low permeability ratio in section 5 .

[23] Cobbold et al. [2001] measured the yield envelopes for various fractions of sand. They determined a coefficient of internal friction, ranging from 0.45 (sand 1) to 0.57 for poured or loose sand (sand 2). They also found that the cohesion increased with the grain size, from zero for sand 3, to $160 \mathrm{~Pa}$ for sand 1. As shown by Mourgues and Cobbold [2003], those values of internal friction were underestimated and the cohesion was overestimated, because the experimenters neglected sidewall friction in their shear test apparatus. We now know that the three fractions have similar angles of internal friction, but different values of cohesion. In fact, the coarse sand (sand 1) is on the whole slightly more resistant than sands 2 and 3.

[24] In sandbox models involving high fluid pressure, effective stresses are as small as a few Pascal. Mourgues and Cobbold [2003] devised shear tests and extensional tests, involving pore fluid, so as to measure the yield envelope for medium-grained Fontainebleau sand (sand 2) at very small effective stresses $(>5 \mathrm{~Pa})$. For sifted dense sand, they showed that the cohesion was negligible and the coefficient of internal friction was large. For normal stresses larger than $30 \mathrm{~Pa}$, the coefficient of internal friction was between 1.4 and 1.5 , and the yield envelope was straight. For normal stresses smaller than $30 \mathrm{~Pa}$, the coefficient reached a maximal value of 2.5 , as the yield envelope curved toward the origin.

\section{Experimental Results}

[25] We completed three series of experiments. Each model was initially $3.5 \mathrm{~cm}$ thick. A sliding piston deformed

Table 1. Permeability of Model Material

\begin{tabular}{lcc}
\hline Material & Grain Size, $10^{-6} \mathrm{~m}$ & Permeability, $10^{-12} \mathrm{~m}^{2}$ \\
\hline Sand 1 & $315-400$ & $120 \pm 10$ \\
Sand 2 & $200-315$ & $70 \pm 5$ \\
Sand 3 & $<200$ & $30 \pm 5$ \\
\hline
\end{tabular}




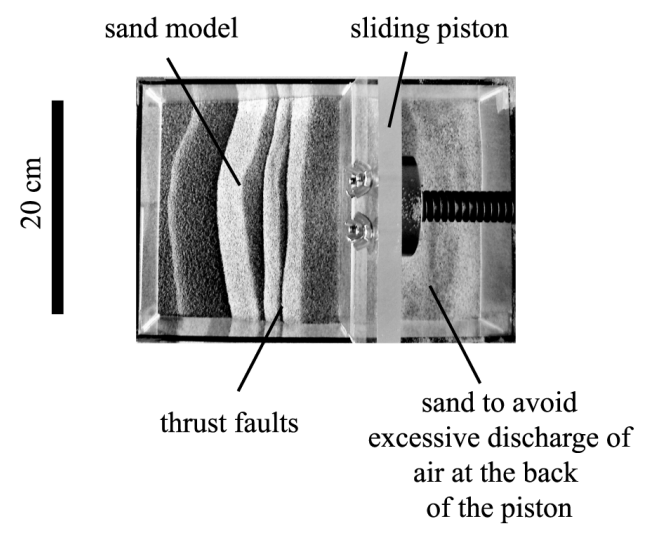

Figure 7. Evidence for small amounts of sidewall friction in an experiment. Piston has moved from right to left, causing the model to shorten and thicken, by formation of thrust faults. Photograph under oblique lighting shows that surface traces of thrust faults are nearly straight.

the upper part of the model, down to $2.5 \mathrm{~cm}$. The piston speed was $20 \mathrm{~cm} /$ hour and the displacement was limited to $10 \mathrm{~cm}$. Although the speed may seem high for analogue modeling, it is extremely low in comparison with the diffusion time $(1 \mathrm{~ms})$ for fluid pressure in the model (see section 3.1 and Appendix A). As a result, it is reasonable to estimate the overpressure distribution in the model, by assuming steady flow at any instant in time. However, so far we have not been able to monitor fluid pressure within the sand models.

[26] In each series of experiments, models deformed under conditions of (1) no overpressure, (2) medium overpressure, or (3) high overpressure. By medium pressure, we mean that $\lambda^{*}=0.6$ at the base of the upper part which deformed. For high overpressure, $\lambda^{*}=0.8$. The uncertainty on $\lambda^{*}$ is 0.05 , because of possible leakage of fluid between pressure chamber and model.

\subsection{Series A}

[27] Series A was designed to investigate the deformation of homogeneous sand packs at various fluid pressures. To build the models, we sifted coarse sand (sand 1) through a sieve. Photographs of the deforming models were taken through the glass sidewall. Because of low friction between glass and sand, boundary effects were not very strong, thrust faults had straight surface traces (Figure 7), and deforma- tion, as observed through the sidewall, was similar to that in the central part of model. Because the material was initially homogeneous, the calculated profiles of fluid pressure, before deformation, are straight lines (Figure 8a).

[28] For no overpressure (experiment A1), the deformation history was typical of a Coulomb wedge (Figure 9a).

[29] 1. The average surface slope was steep (about $35^{\circ}$ ).

[30] 2. Forethrusts propagated from the bottom of the piston to the front of the wedge.

[31] 3. Forethrusts formed and stacked in sequence, older ones becoming inactive as new ones appeared.

[32] 4. All forethrusts were relatively planar.

[33] 5. There were no backthrusts (except against the piston).

[34] At high fluid pressure (experiment A3), the deformation history was markedly different (Figure 9c).

[35] 1. The surface slope was much less steep (about $13^{\circ}$ ) and internal deformation was more widespread.

[36] 2. In the early stages of deformation, two forethrusts appeared simultaneously.

[37] 3. Then a horizontal detachment seemed to form near the bottom of the piston.

[38] 4. The next forethrust was steep and rooted into the detachment surface.

[39] 5. Subsequently, the detachment migrated upward through the material, until the latest thrust had become straighter, linking the surface to the bottom of the piston.

[40] 6. The above process repeated. Migration of the detachment and the overlying forethrusts gave a ductile appearance to the deformation. Although at the surface the deformation was clearly localized on stationary thrusts, at depth the deformed layers looked like folds.

[41] 7. Later thrusts reached the surface at distances of 3 or $4 \mathrm{~cm}$ in front of the advancing wedge, but older ones remained active.

[42] At medium fluid pressure (experiment A2), the deformation history was intermediate between the two extremes (Figure 9b).

[43] 1. The surface slope was about $25^{\circ}$.

[44] 2. Forethrusts formed and stacked in sequence.

[45] 3. Thrusts migrated to some extent through the material.

[46] 4. The last forethrust appeared $4 \mathrm{~cm}$ in front of the wedge, above a basal detachment.

[47] 5. There were no backthrusts (except against the piston).

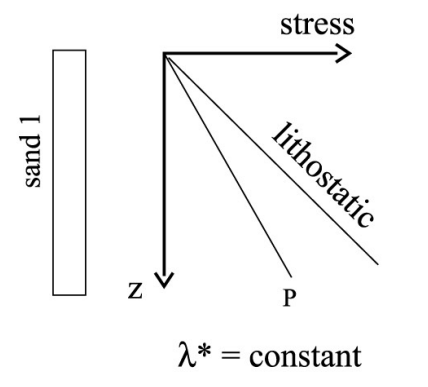

a - Experiments with homogeneous sand (series A)

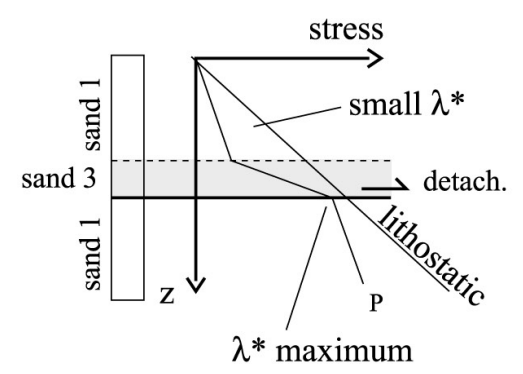

b - Experiments with high permeability ratio (series B)

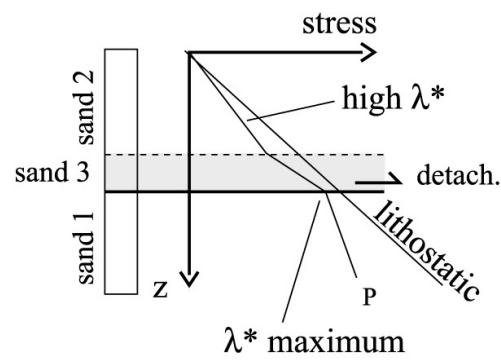

$$
\begin{gathered}
\mathrm{b} \text { - Experiments with } \\
\text { low permeability ratio (series } \mathrm{C} \text { ) }
\end{gathered}
$$

Figure 8. Calculated profiles of fluid pressure before deformation, for experimental series A, B, and C. 


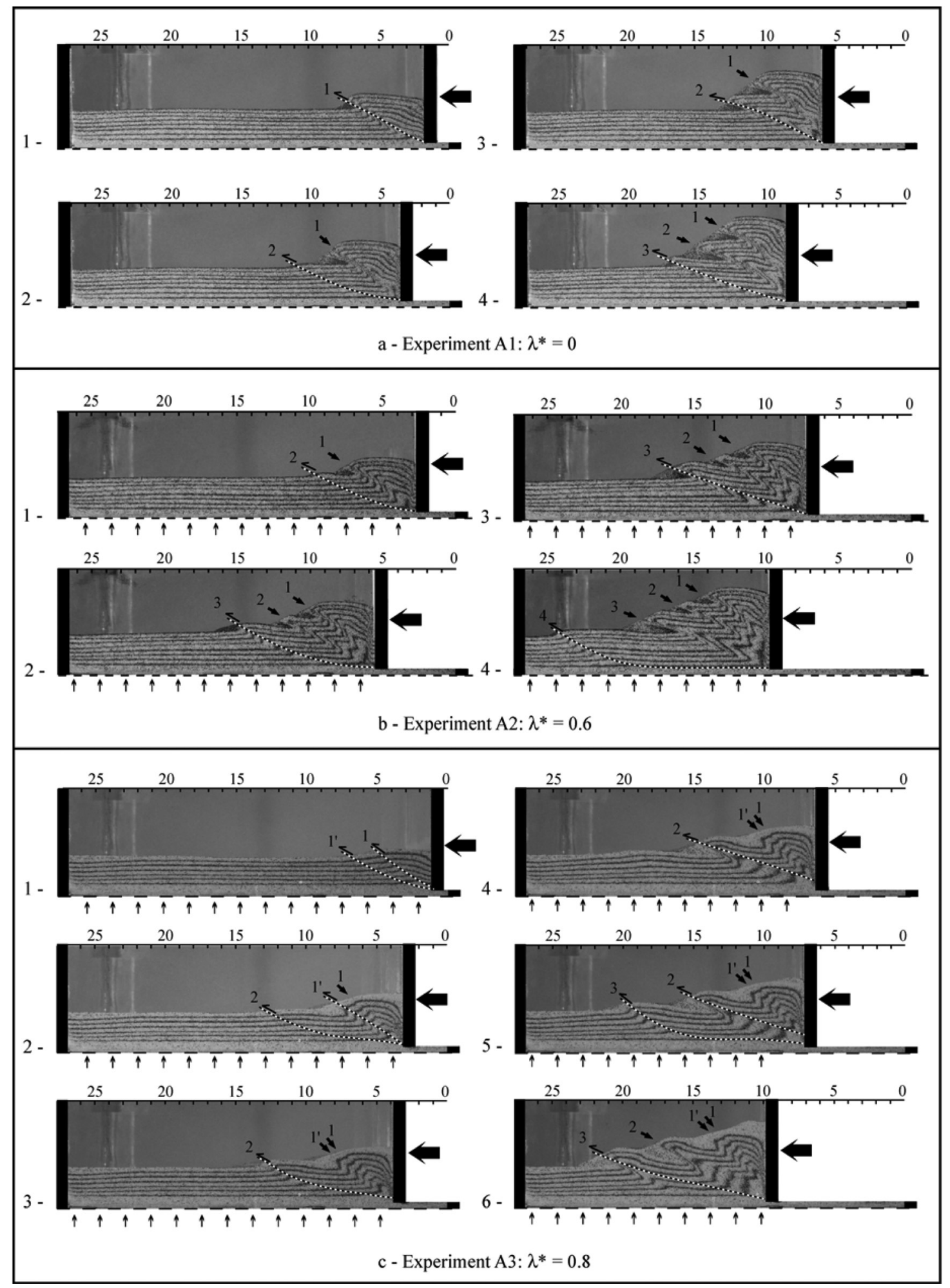

Figure 9. Series A, experiments with homogeneous sand. (a) Experiment with no fluid overpressure. (b) Experiment at medium fluid pressure. (c) Experiment at high fluid pressure. Dotted lines are traces of active faults. Numbers refer to order of appearance.

\subsection{Series $B$}

[48] Models of series B were multilayered. The basal layer was of small permeability (sand 3 ) and $10 \mathrm{~mm}$ thick. The overlying layer $(1.5 \mathrm{~cm}$ thick) and the layer next to the sieve (which did not deform) were of coarse sand (sand 1).
The permeability ratio between the two sands was about $4: 1$. As a result, the predicted pressure profiles in the models were multilinear and the pressure approached lithostatic values beneath the sealing layers of small permeability (Figure $8 \mathrm{~b}$ ). These sealing layers are easy to identify on 


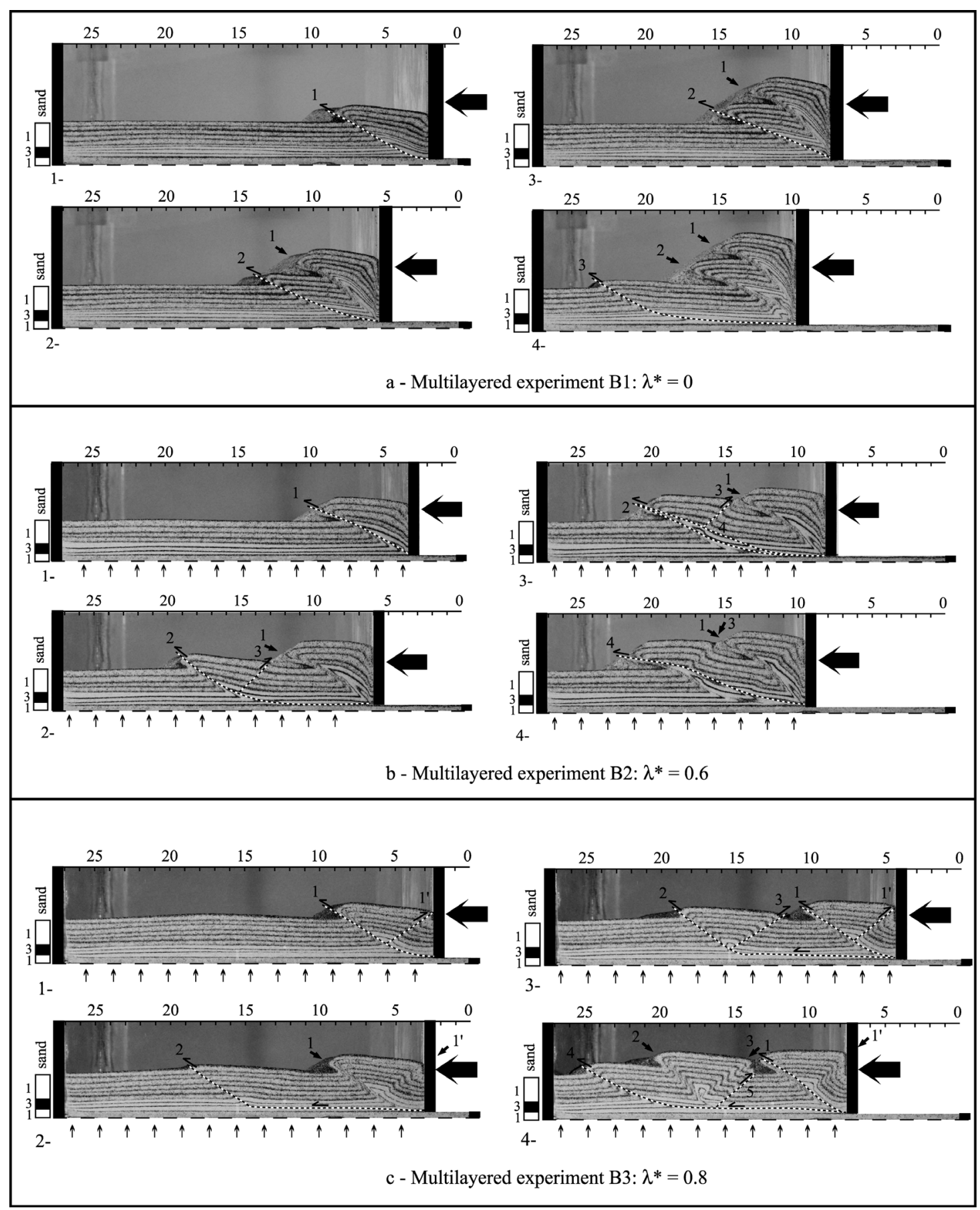

Figure 10. Series B, multilayered models with high permeability ratio. (a) Experiment with no fluid overpressure. (b) Experiment at medium fluid pressure. (c) Experiment at high fluid pressure. Dotted lines are traces of active faults. Numbers refer to order of appearance.

photographs (Figure 10) because they appear less grainy than the coarser sand.

[49] For no overpressure (experiment B1, Figure 10a), the results were similar to those of experiment A1 (Figure 9a), except that at the end of the experiment, a thrust formed far ahead of the wedge. It probably reflected slightly different mechanical behavior of the fine sand.

[50] At high fluid pressure (Figure 10c), deformation was radically different from that of series $\mathrm{A}$.
[51] 1. Deformation propagated far from the piston as a series of symmetric pop-ups (between alternating forethrusts and backthrusts), which took root in the layer of small permeability.

[52] 2. The final wedge was long and low and had a very small apical angle.

[53] 3. The first forethrust was soon followed by a backthrust. No such backthrust formed in experiments of series A. 

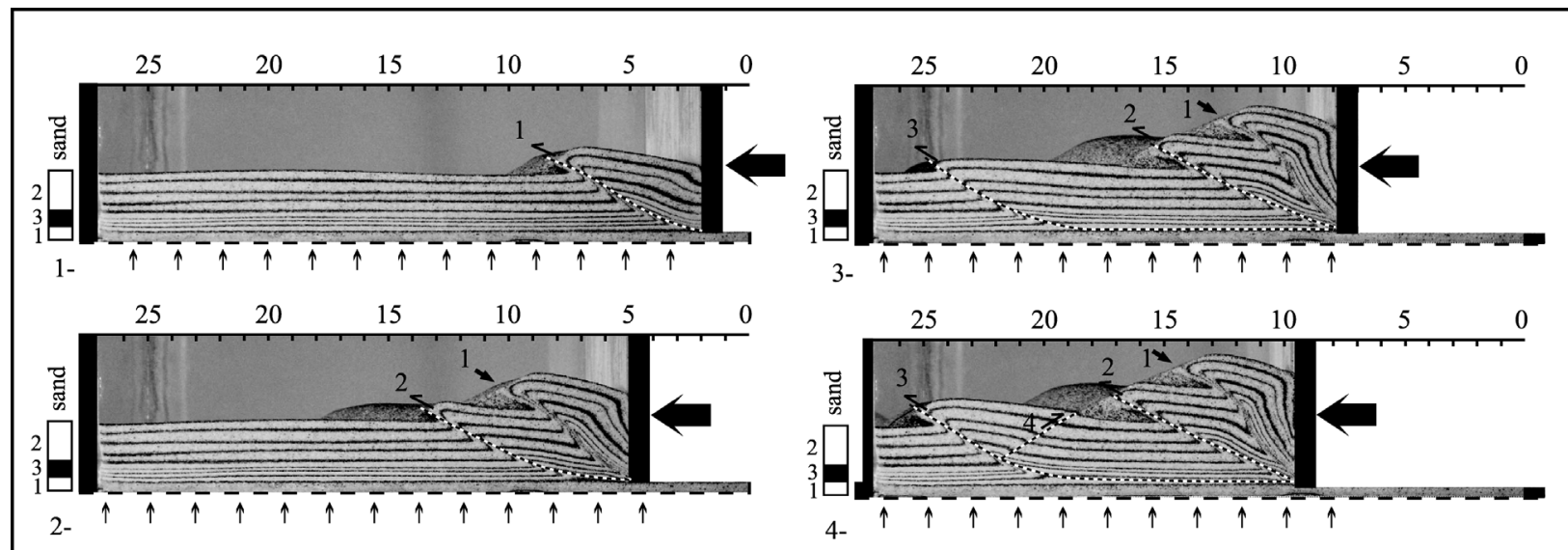

a - Multilayered experiment $\mathrm{C} 2: \lambda^{*}=0.6$
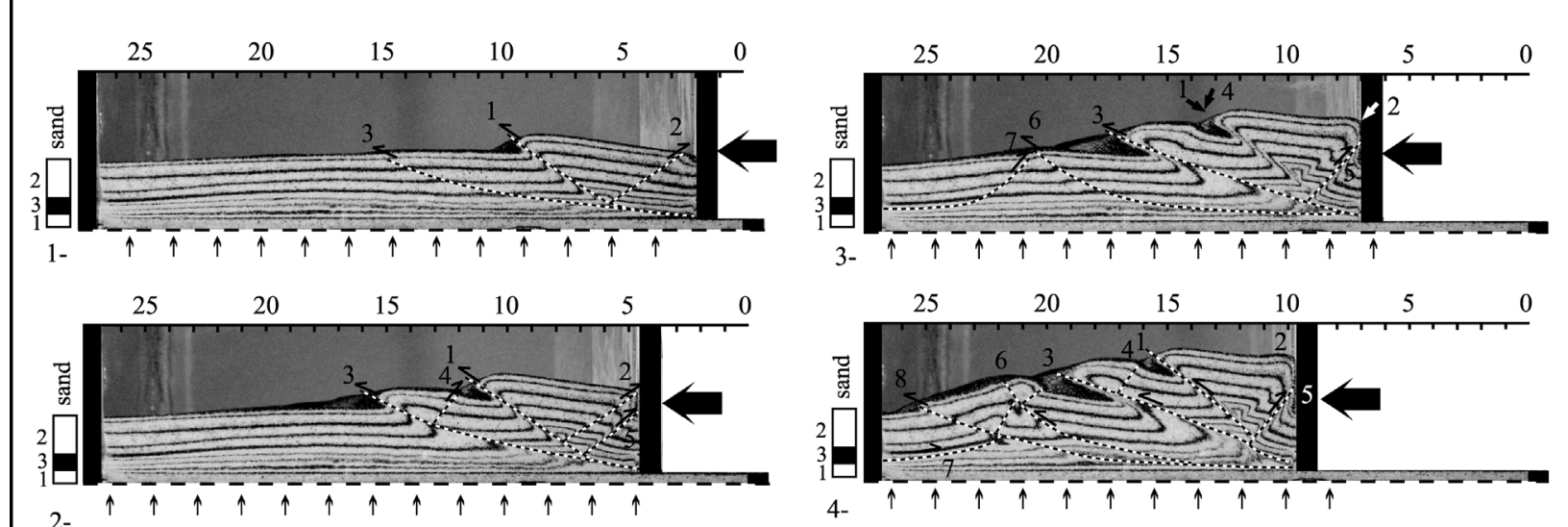

b - Multilayered experiment $\mathrm{C} 3: \lambda^{*}=0.8$

Figure 11. Series $\mathrm{C}$, multilayered models with low permeability ratio. (a) Experiment at medium fluid pressure. (b) Experiment at high fluid pressure. Dotted lines are traces of active faults. Numbers refer to order of appearance.

[54] 4. After $3 \mathrm{~cm}$ of shortening, a thin horizontal crack, $12 \mathrm{~cm}$ long, formed in the layer of fine sand ahead of the first pop-up. At its end, a second pop-up formed while the crack sheared, serving as an efficient detachment.

[55] 5. The second pop-up appeared while the first one was still active.

[56] 6. Toward the end of the experiment, deformation reached the opposite end of the box. The first pop-up reactivated and a new backthrust (fault 5) formed behind the second pop-up.

[57] At medium fluid pressure (Figure 10b), deformation was slightly different.

[58] 1. The first forethrust was not followed by a backthrust.

[59] 2. After $4.5 \mathrm{~cm}$ of shortening, a second forethrust formed, close to the first one.

[60] 3. At this stage, a first backthrust appeared (fault 3).

[61] 4. Before the intervening pop-up had amplified significantly, a new planar section of forethrust appeared (fault 4), joining the base of the piston to the free surface.

\subsection{Series $C$}

[62] Models of series $\mathrm{C}$ were similar to those of series $\mathrm{B}$. They differed only in their upper parts, where medium sand (sand 2) replaced the coarse sand. Thus the permeability ratio between the layer of fine sand and the upper layer was smaller (2.3:1). For the same pressure at the bottom of the confining layer, fluid pressure in the upper part was higher than in series B (Figure 8c).

[63] For no overpressure (results not illustrated), deformation was similar to that of experiment B1.

[64] At high fluid pressure (Figure 11b), deformation propagated more rapidly.

[65] 1. In the early stages, a pop-up developed (as in experiment B3).

[66] 2. Soon afterward, a second forethrust formed, in front of the first pop-up. As in experiment A3, the thrust migrated slightly through the material, becoming straighter.

[67] 3. A second backthrust developed, more superficially.

[68] 4. By the end of the experiment, as many as 8 faults had formed, but deformation was diffuse and had a ductile appearance. 
[69] At medium fluid pressure (Figure 11a), two forethrusts piled up, before a detachment appeared at the base of the fine sand, followed by a distal pop-up.

\section{Discussion}

[70] Our results are similar to those of Cobbold et al. [2001], but our boundary conditions were closer to those of the critical taper model and our experiments had better resolution. We have been able to check some of the predictions of the model and to define some characteristic features of deformed overpressured wedges.

[71] 1. The critical angle of taper depends on the magnitudes of fluid pressure, acting on the basal detachment and within the wedge. Like Cobbold et al. [2001], we cannot rigorously compare all of our results with Dahlen's theory, because of (1) the uncertainty on $\lambda^{*},(2)$ the sensitivity of the theoretical solution in situations where $\mu \approx \mu_{b}$ (as in series A), and (3) the difficulty of measuring an average surface slope for our wedges, which probably had not reached steady states. Nevertheless, on the whole, the fit between theory and experiment is reasonable. For example, for experiment B3 $\left(\mu=1.2, \lambda=0.6, \mu_{b}=1, \lambda \frac{*}{b}=0.8\right)$, the critical taper model predicts a surface slope of $4^{\circ}$ and this is close to what appeared (Figure 10c).

[72] 2. Fault shapes within the wedge depend on permeability contrasts between layers (Figure 12). In the homogeneous model (A3), which deformed at high fluid pressure, the first structures to develop were a flat-lying basal detachment and its frontal thrust ramp. However, these then migrated upward through the material, to form a single and more planar thrust fault (Figure 12b). In the multilayered experiments (B3 and C3), detachments formed readily, beneath or within layers of small permeability, at points where fluid pressures approached lithostatic values (Figure 8). Where the permeability ratio was larger (experiment B3), the detachment was more efficient and resulted in a welldeveloped pop-up. Where the permeability ratio was smaller (experiment C3), deformation occurred more readily in the uppermost layer and propagated less far forward. The apical angle of the wedge was therefore bigger, as predicted by Dahlen's theory. In general, the permeability ratio is fundamental, because it determines the ratio of shear resistances [Cobbold et al, 2001]. In our experiments, the permeability ratio was no greater than $4: 1$, but in nature it can be as large as 1000:1 or more.

[73] 3. In experiments at high fluid pressure, deformation localized less readily and less sharply. In the early stages of experiment A3, two forethrusts developed simultaneously. In experiments $\mathrm{A} 3$ and $\mathrm{C} 3$, thrusts migrated through the material, leaving behind bands of more diffuse deformation that had a ductile appearance. In experiment $\mathrm{C} 3$, newer faults appeared in sequence, as older ones became less active. What were the reasons for such behavior? If localization was due to strain softening [Mandl et al., 1977], then perhaps the softening was less efficient at small effective stresses. Alternatively, localization may have responded to varying overpressures. Unfortunately, we were not able to measure fluid pressures within the models. However, we can calculate them. For thrust zones developing in sand, Colletta et al. [1991] measured an increase in porosity of up to $30 \%$, using X-ray tomography. To a good first approx-

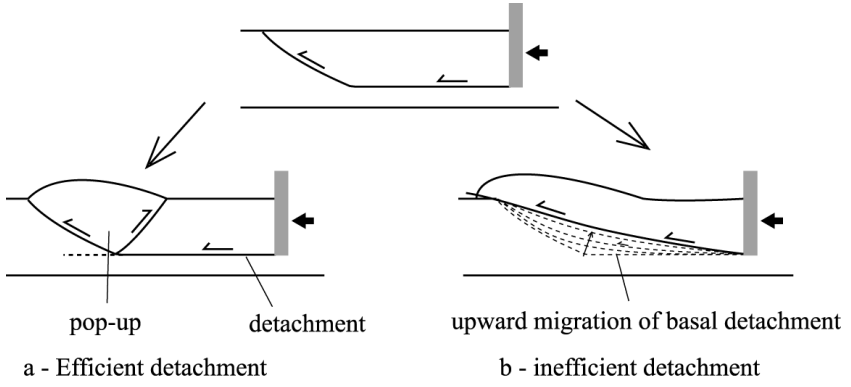

Figure 12. Schematic development of a detachment associated with a thrust. If basal detachment is efficient enough, a backthrust develops and forms a pop-up. Otherwise, detachment migrates through material, to produce a single planar thrust fault.

imation, the permeability of a homogeneous sand increases with the square of the porosity [Cobbold et al., 2001]. Therefore we estimate that the permeability increased by some $70 \%$ in the thrust zones of our models. We have evaluated the effect of such an increase, by means of a simple two-dimensional numerical model for Darcy flow. This shows that thrust faults in sand act as drains, reducing the value of $\lambda^{*}$ at depth by about $10 \%$ in the footwall, but by as little as $2 \%$ in the hanging wall (Figure 13). The relatively high values of $\lambda^{*}$ in the hanging wall should make it weaker than elsewhere and thus may account for upward migration of faults, as observed in the experiments at high fluid overpressures.

\section{Conclusions}

[74] We have used the technique of injecting air into sand, to model the development of thrust wedges where there are fluid overpressures. The models were scaled for stress and for quasi-steady fluid pressure, but not for transitory variations in fluid pressure. We have built a new experimental apparatus, which provides for a horizontally varying fluid pressure, as in the critical taper model of Dahlen.

[75] We have carried out three series of experiments, involving horizontal shortening of homogeneous or multilayered sand, for various gradients of fluid pressure. We were able to follow the deformation during experiments and so collected more information than Cobbold et al. [2001]. The main results follow.

[76] 1. As predicted by the critical taper model, the apical angle of the resulting wedge depends on the overpressure gradients within the wedge and at its base.

[77] 2. In homogeneous sand, at high fluid pressure gradients, deformation becomes diffuse and looks ductile.

[78] 3. In multilayered models, detachments form beneath layers of small permeability, so that thrusts propagate rapidly toward the undeformed foreland. At high fluid overpressures, quasi-symmetric pop-ups form between forethrusts and backthrusts. The efficiency of the detachment and its ease of propagation depend on the fluid pressure, but also on the permeability ratios between the various layers.

[79] Our results have consequences for future studies of accretionary prisms and thrust wedges.

[80] 1. The experiments bear out the predictions of the critical taper model of Dahlen. Like the theory, the experi- 


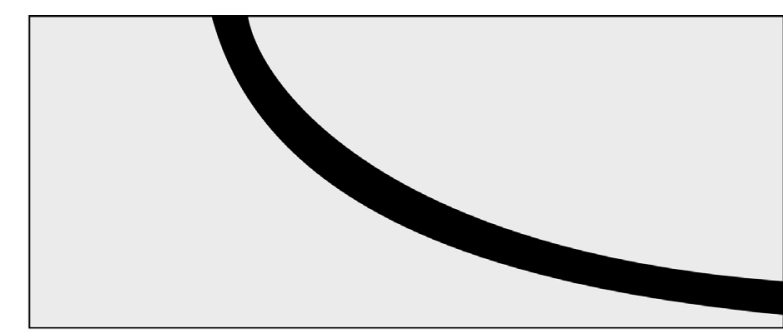

\section{a- Fault with an higher permeability}

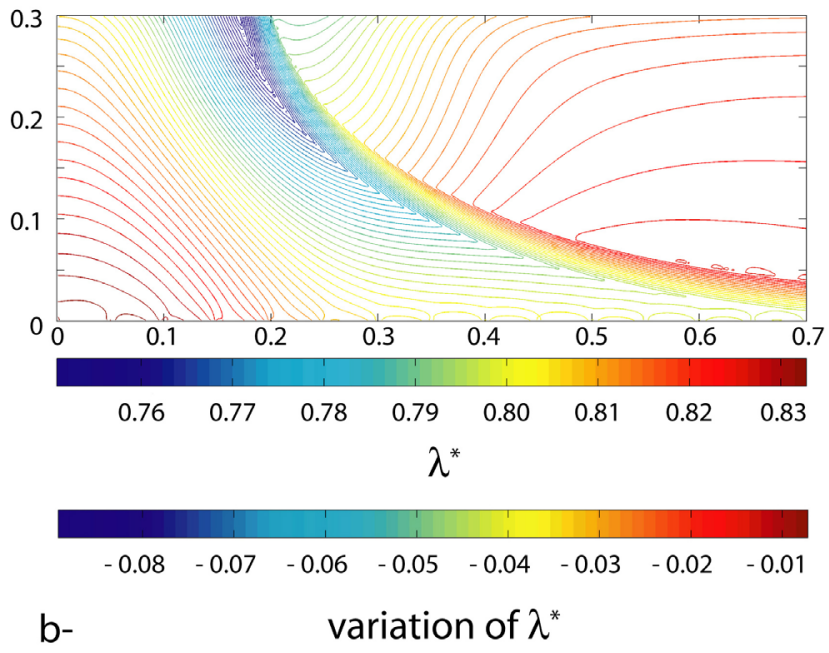

Figure 13. Distribution of fluid overpressure around a permeable thrust fault in a sandbox model. Overpressures (contoured for values of lambda) were obtained by solving equations of steady Darcy flow. As in experiments, model was a wedge of sand, $3 \mathrm{~cm}$ thick (illustrated), overlying a uniform sand pack, $20 \mathrm{~cm}$ thick (not illustrated). Permeability was uniform, except within thrust zone (dark stripe), where it was $70 \%$ smaller. Fluid pressure was uniform at upper and lower boundaries (atmospheric at top of model, $3000 \mathrm{~Pa}$ at base of sand pack). Lateral boundaries were impervious.

ments illustrate the importance of seepage forces in governing the dynamic equilibrium of a wedge. Numerical models should incorporate such forces, if they are properly to simulate the structural development of a wedge.

[81] 2. In the models where a basal layer had a relatively low permeability, the small apical angle and the quasisymmetric style of pop-ups indicated that the principal stress was nearly horizontal, as predicted by the critical taper model. The structures strongly resembled those visible near the leading edges of accretionary prisms, such as the Nankai prism [G. F. Moore et al., 1990].

[82] 3. The experiments have shown that permeability is a first-order property of the material in a wedge. For an overpressured wedge, permeability is probably more significant than the coefficients of friction. The future success of numerical and physical models will depend primarily on our ability to measure or to estimate permeability in nature [Moore and Vrolijk, 1992].

[83] 4. The experiments bear out the common observation that basal detachments in nature form beneath sealing layers of low permeability. The question arises as to whether overpressured fluids have their sources beneath those layers (as in our models), or within them. Further observations on pressure distributions and reaction kinetics in natural wedges, and further numerical or physical modeling, are required to answer such questions.

\section{Appendix A: Transitory Variations in Fluid Pressure and Their Scaling}

[84] In the Earth's crust, pore fluid pressure tends to increase with depth, as a result of gravity. If the pores are interconnected, the pressure gradient will be hydrostatic. This can be taken as a reference state. Overpressures (or underpressures) can develop, if some mechanism disturbs this reference state. However, abnormal pressures will tend to dissipate, as soon as the generating mechanism stops and provided that the rocks are permeable. In practice, therefore overpressures are likely to be transitory [Neuzil, 1994].

[85] For the generation of fluid overpressure in situ, several mechanisms have been suggested [Osborne and Swarbrick, 1997; Swarbrick et al., 2002]. They may result from either (1) a reduction in the pore space, due to contraction of the solid matrix, or (2) an increase in the volume of pore fluid.

[86] In a porous elastic material, fluid pressure can vary in space and time, in sympathy with the mean total stress [Ge and Garven, 1992; Neuzil, 1995; Shi and Wang, 1986]:

$$
\left.\frac{k}{v_{f}} \nabla^{2} P\right|_{n h}+\alpha_{b} \frac{d \sigma_{t}}{d t}=\left[\phi \beta-\phi \beta_{s}+\alpha_{b}\right] \frac{d P}{d t}+Q
$$

Here $\left.P\right|_{n h}$ is the nonhydrostatic part of the pore pressure (in other words, the overpressure or underpressure) that drives fluid flow, $\sigma_{t}$ is the mean total stress, $\alpha_{b}$ is the bulk compressibility, $\beta_{s}$ and $\beta$ express the compressibility of solid grains and pore fluid, respectively, and $Q$ is an internal source of fluid pressure (for example, by gas generation).

[87] Equation (A1) is a generalized equation of diffusion. It expresses the fact that any fluctuation in fluid pressure has three potential contributions. One of them is the source term, Q. Another is the variation in mean stress resulting from compaction:

$$
\frac{\alpha}{\phi \beta-\phi \beta_{s}+\alpha_{b}} \frac{d \sigma_{t}}{d t}
$$

The third is the pressure gradient, which derives from Darcy's law and governs fluid flow:

$$
\left.\frac{k}{\left(\phi \beta-\phi \beta_{s}+\alpha_{b}\right) \nu_{f}} \nabla^{2} P\right|_{n h}
$$

Typically, $\beta=4 \times 10^{-10} \mathrm{~Pa}^{-1}$ for water and $\beta_{s}=10^{-11} \mathrm{~Pa}^{-1}$ for solid grains. The bulk compressibility $\alpha_{b}$, depends mainly on the solid matrix and ranges from $10^{-8}$ to $10^{-11} \mathrm{~Pa}^{-1}[\mathrm{Ge}$ and Garven, 1992; Shi and Wang, 1986], depending on the state of compaction. As a first approximation, we shall neglect $\beta_{s}$ in comparison with $\alpha_{b}$, so that equation (A1) becomes

$$
\left.\frac{k}{\nu_{f}} \nabla^{2} P\right|_{n h}+\alpha_{b} \frac{d \sigma_{t}}{d t}=\left[\phi \beta+\alpha_{b}\right] \frac{d P}{d t}+Q
$$


[88] Equation (A2) is valid for elastic deformation. In nature, however, most deformation is nonelastic and irrecoverable. For large deformation, the compressibility, as measured on samples of sediment, is not necessary representative of the overall behavior. Neuzil [1986] has suggested using a higher compressibility, to take this disparity into account.

[89] For equation (A2), we can distinguish two timescales: one $\left(T_{c}\right)$ for the buildup of pressure, and the other $\left(T_{d}\right)$ for its dissipation.

\section{A1. Buildup of Overpressure by Loading Without Drainage}

[90] If the load increases quickly (due, for example, to a rapid rate of sedimentation or to tectonic thickening) and the permeability is small enough, $T_{c}<<T_{d}$, and diffusion can be neglected, so that equation (A2) becomes

$$
\frac{d P}{d t}=\frac{\alpha_{b}}{\left[\phi \beta+\alpha_{b}\right]} \frac{d \sigma_{t}}{d t}
$$

Here we have assumed that the source, $Q$, is also negligible. For young and readily compactable sediment, $\alpha_{b}>\beta$, so that equation (A3) integrates to

$$
\Delta P=\Delta \sigma_{t}
$$

The scaling of equation (A4) does not imply any strong relationship between values of compressibility for matrix and fluid. Model materials must simply satisfy

$$
\alpha_{b}>>\beta
$$

Young's modulus for loose and dense sands ranges between 10 and $50 \mathrm{MPa}$. Thus the compressibility $\alpha_{b}$ is around $10^{-7} \mathrm{~Pa}^{-1}$ or less, if we assume irreversible deformation. Water as an experimental pore fluid satisfies condition (A5), because $\beta=4 \times 10^{-10} \mathrm{~Pa}^{-1}$. On the other hand, condition (A5) does not hold for air, because $\beta=$ $10^{-5} \mathrm{~Pa}^{-1}$, so that from (A3), the change in fluid pressure will be no more than $1 \%$ of the change in stress, $\Delta \sigma_{t}$.

\section{A2. Dissipation of Overpressure}

[91] Now consider that $\sigma_{t}$ is invariant. Equation (A2) becomes

$$
\frac{\partial P}{\partial t}=-\left.\frac{k}{\left(\alpha_{b}+\phi \beta\right) \nu_{f}} \nabla^{2} P\right|_{n h}
$$

We also assume that $Q$ vanishes and that $\alpha_{b}>>\beta$.

[92] Equation (A6) governs the dissipation of overpressure by a diffusion mechanism (Darcy flow). The reference time for this diffusion is

$$
t_{0}=\frac{\nu_{0} \chi_{0} L_{0}^{2}}{k_{0}}
$$

Here, $\chi_{0}=\left(\alpha_{b 0}+\phi \beta_{0}\right)$. The reference time increases with fluid viscosity, hydraulic resistivity $\left(1 / \mathrm{k}_{0}\right)$ and compressibility. The time ratio is therefore

$$
\gamma_{t}=\gamma_{\nu} \gamma_{L}^{2} \gamma_{\chi} \gamma_{k}^{-1}
$$

In their experiments, Cobbold et al. [2001] applied Darcy's law:

$$
q_{i}=-\left.\frac{k}{v_{f}} \frac{\partial P}{\partial x_{i}}\right|_{n h}
$$

The time ratio deduced from equation (A9) is slightly different:

$$
\gamma_{t}=\gamma_{\nu} \gamma_{L}^{2} \gamma_{\sigma}^{-1} \gamma_{k}^{-1}
$$

[93] If the elastic properties of the material are properly scaled, we must have $\gamma_{\sigma}=\gamma_{x}^{-1}$ [Hubbert, 1937], so that equations (A8) and (A10) become identical. In contrast, if the elastic properties of a model material are not properly scaled, as so often happens in practice [Ramberg, 1967], equation (A8) may be preferable.

[94] In the preceding paragraph, we have demonstrated that water makes a good pore fluid for modeling the generation of pressure by compaction. By assuming reference values of $k_{m}=5 \times 10^{-11} \mathrm{~m}^{2}, k_{r}=10^{-16} \mathrm{~m}^{2}, \alpha_{b r}=$ $10^{-8} \mathrm{~Pa}^{-1}, \alpha_{b m}=10^{-7} \mathrm{~Pa}^{-1}$ and $\gamma_{\mathrm{L}}=10^{-5}$, the time ratio is $2 \times 10^{-15}$. This means that 1 second in an experiment is equivalent to $15 \mathrm{Ma}$ in nature! The reference time for diffusion in a sand model, $3 \mathrm{~cm}$ thick, is close to $2 \mathrm{~ms}$, if the fluid is water, and $1.5 \mathrm{~ms}$, if it is air. This means that although we can model the generation of fluid overpressures by a compaction mechanism when the material is very compressible, dissipation is quasi-instantaneous. Thus properly scaled analogue modeling of such transitory phenomena, using air or water as a pore fluid and sand as a brittle material, would seem to be impossible. In addition, it may be difficult to model any changes in permeability during faulting.

\section{References}

Adam, J., J. L. Urai, B. Wieneke, O. Oncken, K. Pfeiffer, N. Kukowski, J. Lohrmann, S. Hoth, W. van der Zee, and J. Schmatz (2005), Shear localization and strain distribution during tectonic faulting: New insights from granular-flow experiments and high-resolution optical image correlation techniques, J. Struct. Geol., 27, 283-301.

Bangs, N. L. B., T. H. Shipley, J. C. Moore, and G. F. Moore (1999), Fluid accumulation and channeling along the northern Barbados Ridge decollement thrust, J. Geophys. Res., 104, 20,399-20,414.

Bangs, N. L., T. Shipley, S. Gulick, G. Moore, S. Kuromoto, and Y. Nakamura (2004), Evolution of the Nankai Trough décollement from the trench into the seismogenic zone: Inferences from three-dimensional seismic reflection imaging, Geology, 32(4), 273-276.

Bekins, B., A. M. McCaffrey, and S. J. Dreiss (1994), Influence of kinetics on the smectite illite transition in the Barbados accretionary prism, J. Geophys. Res., 99, 18,147-18,158.

Bekins, B., A. M. McCaffrey, and S. J. Dreiss (1995), Episodic and constant flow for the origin of low-chloride waters in a modern accretionary complex, Water Resour. Res., 31(12), 3205-3215.

Brown, K., and G. K. Westbrook (1988), Mud diapirism and subcretion in the Barbados Ridge accretionary complex: The role of fluids in accretionary processes, Tectonics, 7(3), 613-640.

Cobbold, P. R. (1999), Hydrocarbon generation, fluid overpressure and source rock detachments in thrust belts, paper presented at Thrust Tectonics 99, Royal Holloway, Univ. of London, London.

Cobbold, P. R., and L. Castro (1999), Fluid pressure and effective stress in sandbox models, Tectonophysics, 301, 1-19. 
Cobbold, P. R., S. Durand, and R. Mourgues (2001), Sandbox modelling of thrust wedges with fluid-assisted detachments, Tectonophysics, 334, $245-258$

Colletta, B., J. Letouzey, R. Pinedo, J. F. Ballard, and P. Balé (1991), Computerized X-ray tomography analysis of sandbox models: Examples of thin-skinned thrust systems, Geology, 19, 1063-1067.

Couzens-Schultz, B. A., B. C. Vendeville, and D. V. Wiltschko (2003) Duplex style and triangle zone formation: Insights from physical modeling, J. Struct. Geol., 25, 1623-1644.

Dahlen, F. A. (1984), Non-cohesive critical Coulomb wedges: An exact solution, J. Geophys. Res., 89, 10,125-10,133.

Dahlen, F. A. (1990), Critical taper model of fold-and-thrust belts and accretionary wedges, Annu. Rev. Earth Planet. Sci., 18, 55-99.

Dahlen, F. A., and T. D. Barr (1989), Brittle frictional mountain building: 1. Deformation and mechanical energy budget, J. Geophys. Res., 94 3906-3922.

Dahlen, F. A., J. Suppe, and D. Davis (1984), Mechanics of fold-and-thrust belts and accretionary wedges: Cohesive Coulomb theory, J. Geophys. Res., 89, 10,087-10,101.

Davis, D. M., and T. Engelder (1985), The role of salt in fold-and-thrust belts, Tectonophysics, 119, 67-88.

Davis, D., J. Suppe, and F. A. Dahlen (1983), Mechanics of fold-and-thrust belts and accretionary wedges, J. Geophys. Res., 88, 1153-1172.

Echevarria, L., R. Hernandez, R. Allmendinger, and J. Reynolds (2003), Subandean thrust and fold belt of northwestern Argentina: Geometry and timing of the Andean evolution, AAPG Bull., 87(6), 965-985.

Ellis, S., G. Schreurs, and M. Panien (2004), Comparisons between analogue and numerical models of thrust wedge development, J. Struct. Geol., 26 , $1659-1675$.

Ge, S., and G. Garven (1992), Hydromechanical modeling of tectonically driven groundwater flow with application to the Arkoma foreland basin, J. Geophys. Res., 97, 9119-9144.

Gutscher, M. A., N. Kukowski, J. Malavieille, and S. Lallemand (1996), Cyclical behavior of thrust wedges: Insights from high basal friction sandbox experiments, Geology, 24(2), 135-138.

Gutscher, M. A., N. Kukowski, J. Malavieille, and S. Lallemand (1998a), Episodic imbricate thrusting and underthrusting: Analog experiments and mechanical analysis applied to the Alaskan accretionary wedge, J. Geophys. Res., 103, 10,161-10,176.

Gutscher, M. A., N. Kukowski, J. Malavieille, and S. Lallemand (1998b), Material transfer in accretionary wedges from analysis of a systematic series of analog experiments, J. Struct. Geol., 20, 407-416.

Henry, P. (2000), Fluid flow at the toe of the Barbados accretionary wedge constrained by thermal, chemical and hydrogeologic observations and models, J. Geophys. Res., 105, 25,855-25,872.

Hubbert, M. K. (1937), Theory of scale models as applied to the study of geologic structures, Geol. Soc. Am. Bull., 48, 1459-1520.

Hubbert, M. K., and W. W. Rubey (1959), Role of fluid pressure in mechanics of overthrust faulting.1. Mechanics of fluid-filled porous solids and its application to overthrust faulting, Geol. Soc. Am. Bull., $70,115-166$

Kopp, C., J. Fruehn, E. R. Flueh, C. Reichert, N. Kukowski, J. Bialas, and J. Klaeschen (2000), Structure of the Makran subduction zone from wideangle and reflection seismic data, Tectonophysics, 329, 171-191.

Lallemand, S., P. Schmürle, and J. Malavieille (1994), Coulomb theory applied to accretionary and non-accretionary wedges: Possible causes for tectonic erosion and/or frontal accretion, J. Geophys. Res., 99, $12,033-12,055$

Liu, H., K. R. McClay, and D. Powell (1992), Physical models of thrust wedges, in Thrust Tectonics, edited by K. R. McClay, pp.71-82, CRC Press, Boca Raton, Fla.

Lohrmann, J., N. Kukowski, J. Adam, and O. Oncken (2003), The impact of analogue material properties on the geometry, kinematics, and dynamics of convergent sand wedges, J. Struct. Geol., 25, 1691-1711.

Malavieille, J. (1984), Modélisation expérimentale des chevauchements imbriqués: Application aux chaînes de montagnes, Bull. Soc. Geol. Fr. Ser. 7, 26, 129-138.

Maltman, A., P. Labaume, and B. Housen (1997), Structural geology of the décollement at the toe of the Barbados accretionary prism, Proc. Ocean Drill. Program Sci. Results, 156, 279-292.
Mandl, G., L. N. J. D. Jong, and A. Maltha (1977), Shear zones in granular material, Rock Mech., 9, 95-144.

Minshull, T. A., R. S. White, P. J. Barton, and J. S. Collier (1992), Deformation at plate boundaries around the Gulf of Oman, Mar. Geol., 104(14), 265-277.

Moore, G. F., T. H. Shipley, P. L. Stoffa, D. E. Karig, A. Taira, S. Kuramoto, H. Tokuyama, and K. Suyehiro (1990), Structure of the Nankai Trough accretionary zone from multichannel seismic reflection data, J. Geophys. Res., 95, 8753-8765.

Moore, J. C., and H. Tobin (1997), Estimated fluid pressure of the Barbados accretionary prism and adjacent sediments, Proc. Ocean Drill. Program Sci. Results, 156, 229-238.

Moore, J. C., and P. Vrolijk (1992), Fluids in accretionary prisms, Rev. Geophys., 30(2), 113-135.

Moore, J. C., et al. (1988), Tectonics and hydrogeology of the northern Barbados Ridge: Results from the Ocean Drilling Program Leg 110 Geol. Soc. Am. Bull., 100, 1578-1593.

Moore, J. C., D. Orange, and L. D. Kulm (1990), Interrelationship of fluid venting and structural evolution: Alvin observations from the frontal accretionary prism, Oregon, J. Geophys. Res., 95, 8795-8808.

Moore, J. C., et al. (1995), Abnormal fluid pressures and fault-zone dilation in the Barbados accretionary prism: Evidence from logging while drilling, Geology, 23(7), 605-608.

Mourgues, R., and P. R. Cobbold (2003), Some tectonic consequences of fluid overpressures and seepage forces as demonstrated by sandbox modelling, Tectonophysics, 376, 75-97.

Mulugeta, G. (1988), Modelling the geometry of Coulomb thrust wedges, J. Struct. Geol., 10, 847-859.

Mulugeta, G., and H. Koyi (1992), Episodic accretion and strain partitioning in a model sand wedge, Tectonophysics, 202, 319-333.

Neuzil, C. E. (1986), Groundwater flow in low-permeability environments, Water Resour. Res., 22, 1163-1195.

Neuzil, C. E. (1994), How permeable are clays and shales?, Water Resour Res., 30, 145-150.

Neuzil, C. E. (1995), Abnormal pressures as hydrodynamic phenomena, Am. J. Sci. 295, 742-786.

Osborne, M. J., and R. E. Swarbrick (1997), Mechanisms for generating overpressure in sedimentary basins: A reevaluation, AAPG Bull., 81(6), $1023-1041$

Ramberg, H. (1967), Model experimentation of the effect of gravity on tectonic processes, Geophys. J. R. Astron. Soc., 14, 307-329.

Saffer, D. M., and B. A. Bekins (1988), Episodic fluid flow in the Nankai accretionary complex: Timescale, geochemistry, flow rates, and fluid budget, J. Geophys. Res., 103, 30,351-30,370.

Schlüter, H. U., A. Prexl, C. Gaedicke, H. Roeser, C. Reichert, H. Meyer, and C. von Daniels (2002), The Makran accretionary wedge: Sediment thicknesses and ages and the origin of mud volcanoes, Mar. Geol., 185 , $219-232$.

Shi, Y., and C. Y. Wang (1986), Pore pressure generation in sedimentary basins: Overloading versus aquathermal, J. Geophys. Res., 91,2153-2162.

Shi, Y., and C. Y. Wang (1988), Generation of high pore pressures in accretionary prisms: Inferences from the Barbados subduction complex, J. Geophys. Res., 93, 8893-8909.

Storti, F., K. R. McClay, and F. Salvini (1997), Fault-related folding in analogue models of thrust wedges, J. Struct. Geol., 19, 583-602.

Swarbrick, R. E., M. J. Osborne, G. S. Yardley (2002), Comparison of overpressure magnitude resulting from the main generating mechanisms, in Pressure Regimes in Sedimentary Basins and Their Prediction, edited by A. R. Huffman and G. L. Bowers, AAPG Mem., 76, 1-12.

Taira, A., et al. (1992), Sediment deformation and hydrogeology of the Nankai Trough accretionary prism: Synthesis of shipboard results of ODP Leg 131, Earth Planet. Sci. Lett., 109(3-4), 431-450.

P. R. Cobbold, Géosciences-Rennes (UMR 6118), Campus de Beaulieu, Université de Rennes 1, Avenue du Général-Leclerc, F-35042 Rennes Cedex, France. (peter.cobbold@univ-rennes1.fr)

R. Mourgues, LGRMP, Université du Maine, F-72085 Le Mans Cedex 09, France. (regis.mourgues@univ-lemans.fr) 